\title{
LES MANUSGRITS
}

\section{1) \\ CHATEAU DE MERVILLE}

NUTICES, EXTRAITS FT FAC-SIMILES

PAll

\section{DOUAIS}

Professeur à l'Institpt catho'ique de Tonlonge: ... .

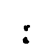

PARIS

ALPHONSE PICARD

Libraire-dditeur,

82 , RUE BONAPARTE, 82
TOULOUSE

ÉDOUARD PRIVAT

Libraire-éditeur,

45, HUk DES TOURNELRS, 45 